\title{
Neuroprotective mechanisms of dieckol against glutamate toxicity through reactive oxygen species scavenging and nuclear factor-like 2/heme oxygenase-1 pathway
}

\author{
Yanji Cui ${ }^{1,4}$, Khulan Amarsanaa ${ }^{1}$, Ji Hyung Lee ${ }^{1}$, Jong-Kook Rhim ${ }^{2,8}$, Jung Mi Kwon ${ }^{3,8}$, Seong-Ho Kim ${ }^{5}$, Joo Min Park ${ }^{6,7}$, \\ Sung-Cherl Jung ${ }^{1,8}$, and Su-Yong Eun ${ }^{1,8, *}$ \\ ${ }^{1}$ Department of Physiology, ${ }^{2}$ Department of Neurosurgery, ${ }^{3}$ Division of Hematology-Oncology, Department of Internal Medicine, Jeju National University \\ School of Medicine, Jeju 63243, Korea, ${ }^{4}$ Neurology 1, The Second Affiliated Hospital of Xinxiang Medical University, Henan 453002, China, ${ }^{5}$ BotaMedi Inc., Jeju \\ 63309, ${ }^{6}$ Center for Cognition and Sociality, Institute for Basic Science (IBS), KAIST, Daejeon 34126, ${ }^{7}$ University of Science and Technology, Daejeon 341 13, ${ }^{8}$ Insti- \\ tute of Medical Science, Jeju National University, Jeju 63243, Korea
}

\section{ARTICLE INFO}

Received November 8, 2018

Revised December 23, 2018

Accepted January 16, 2019

\section{*Correspondence \\ Su-Yong Eun \\ E-mail: syeun@jejunu.ac.kr}

\section{Key Words}

Dieckol

Glutamate toxicity

Heme oxygenase-1

Mitochondria

Neurons

Reactive oxygen species
ABSTRACT Glutamate toxicity-mediated mitochondrial dysfunction and neuronal cell death are involved in the pathogenesis of several neurodegenerative diseases as well as acute brain ischemia/stroke. In this study, we investigated the neuroprotective mechanism of dieckol (DEK), one of the phlorotannins isolated from the marine brown alga Ecklonia cava, against glutamate toxicity. Primary cortical neurons (100 $\mu \mathrm{M}, 24 \mathrm{~h}$ ) and $\mathrm{HT} 22$ neurons (5 mM, $12 \mathrm{~h}$ ) were stimulated with glutamate to induce glutamate toxic condition. The results demonstrated that DEK treatment significantly increased cell viability in a dose-dependent manner (1-50 $\mu \mathrm{M})$ and recovered morphological deterioration in glutamate-stimulated neurons. In addition, DEK strongly attenuated intracellular reactive oxygen species (ROS) levels, mitochondrial overload of $\mathrm{Ca}^{2+}$ and ROS, mitochondrial membrane potential $\left(\Delta \Psi_{\mathrm{m}}\right)$ disruption, adenine triphosphate depletion. DEK showed free radical scavenging activity in the cell-free system. Furthermore, DEK enhanced protein expression of heme oxygenase-1 $(\mathrm{HO}-$ 1), an important anti-oxidant enzyme, via the nuclear translocation of nuclear factorlike 2 (Nrf2). Taken together, we conclude that DEK exerts neuroprotective activities against glutamate toxicity through its direct free radical scavenging property and the Nrf-2/HO-1 pathway activation.

\section{INTRODUCTION}

Glutamate is the major excitatory neurotransmitter in the central nervous system. Glutamatergic synaptic transmission has been implicated in learning and memory, and synaptic plasticity. However, high levels of extracellular glutamate play a hazardous role under certain pathological conditions, which is called glutamate toxicity [1-3]. In the mechanisms underlying glutamate toxicity, there are two pathways triggered by different types of membrane-bound receptors/transporters [4].
The first one, also called excitotoxicity, is triggered by the excessive activation of glutamate receptors including $\mathrm{Ca}^{2+}$ permeable $N$-methyl-D-aspartate receptors (NMDAR) and G protein-coupled metabotropic glutamate receptors (mGluR). The subsequent excessive $\mathrm{Ca}^{2+}$ influx from extracellular space was followed by mitochondrial overload of $\mathrm{Ca}^{2+}$ overload through mitochondrial $\mathrm{Ca}^{2+}$ channels such as mitochondrial calcium uniporter. The reciprocal interaction between mitochondrial $\mathrm{Ca}^{2+}$ $\left(\mathrm{mtCa}^{2+}\right)$ and reactive oxygen species (mtROS) causes vicious mitochondrial dysfunction through a positive feedback mechanism [5].
This is an Open Access article distributed under the terms of the Creative Commons Attribution Non-Commercial License, which permits unrestricted non-commercial use, distribution, and reproduction in any medium, provided the original work is properly cited. Copyright $\odot$ Korean J Physiol Pharmacol, pISSN 1226-4512, eISSN 2093-3827
Author contributions: S.Y.E. conceived and designed experiments, and supervised project. S.Y.E., and Y.C. wrote manuscript. Y.C., K.A., and J.H.L. conducted experiments and analyzed data. S.H.K. prepared dieckol and analyzed data. J.K.R., J.M.K., J.M.P., and S.C.J. gave conceptual advices and analyzed data. All authors discussed the results and commented on the manuscript. 
The other pathway is mediated by cystine/glutamate antiporters in the cell membrane. Cystine uptake from the extracellular space is disturbed by high levels of extracellular glutamate, followed by glutathione (GSH) depletion. These processes lead to lipoxygenase activation and increase ROS levels [6-9].

Both types of these pathways in glutamate toxicity mechanism result in the mitochondrial overload of $\mathrm{Ca}^{2+}$ and ROS via several cellular mechanisms, which is crucial in determining the fate of neuronal cell survival and death [2,3,5]. Mitochondrial overload of $\mathrm{Ca}^{2+}$ and ROS results in mitochondrial membrane potential $\left(\Delta \Psi_{\mathrm{m}}\right)$ disruption, a second boost of ROS generation in mitochondrial electron transport chains (ETC), adenine triphosphate (ATP) depletion, and mitochondrial membrane permeabilization (MMP). Pro-apoptotic Bcl-2 family members-mediated Bak/Bax oligomerization evokes MMP in the outer membrane [7-11]. Proapoptotic factors such as cytochrome $\mathrm{c}$ and apoptosis-inducing factor are released from the mitochondrial intermembrane space through MMP pores and finally cause mitochondria-dependent cell death [12-15]. Neuronal cell death inevitably leads to dysfunction of the nervous system and therefore has been implicated in brain ischemia/stroke, traumatic brain injury, and neurodegenerative diseases [16-18].

Imbalance between intracellular ROS and cellular anti-oxidant enzyme system results in mitochondrial dysfunction and neuronal cellular death against glutamate toxicity. Heme oxygenase-1 (HO-1) plays an important anti-oxidant enzyme which detoxifies ROS through the formation of biliverdin and bilirubin, both of which are exerted as ROS scavengers [19]. Nuclear factor-like 2 (Nrf2), a basic leucine zipper transcription factor, is basally sequestered by kelch-like protein 1 (Keap1). However, in response to certain stimuli, the phosphorylated Nrf2 is released from Keap1 and then translocates to the nucleus where it activates the antioxidant response element in the promoter region of several antioxidant genes such as HO-1 [20,21]. Therefore, Nrf2/HO-1 axis as a cellular anti-oxidant defense system has been extensively investigated in ROS-related neuronal insult models.

Several research groups have shown that dieckol (DEK), one of the phlorotannins isolated from the marine brown alga Ecklonia cava, exhibits multifunctional biological activities such as anti-oxidant, anti-inflammatory, and anti-cancer activities in diverse cell types $[22,23]$ as well as improved cognitive function in ethanol-treated mice [24]. We recently reported that DEK inhibits lipopolysaccharide-stimulated microglia activation and subsequent microglia-mediated neuronal cell death via mitogenactivated protein kinases, Akt, and nicotinamide adenine dinuclelotide phosphate (NADPH) oxidase-mediated pathways [25]. We demonstrate here that DEK exerts neuroprotective activities in glutamate-stimulated neurons against mitochondria-dependent neuronal cell death through its direct free radical scavenging property and the $\mathrm{Nrf} 2 / \mathrm{HO}-1$ pathway activation.

\section{METHODS}

\section{Reagents}

5,5',6,6'-Tetrachloro-1,1',3,3'-tetraethylbenzimidazolocarbocy anine iodide (JC-1), tetramethylrhodamine, ethyl ester, rhod-2 acetoxymethyl ester (Rhod-2 AM), MitoTracker Green, MitoSOX Red, ATP determination kit, and reagents used in cell culture were obtained from Invitrogen (Carlsbad, CA, USA). Antibodies against Nrf2, HO-1, and $\beta$-actin were purchased from Santa Cruz Biotechnology Inc. (Santa Cruz, CA, USA). The antibody against the TATA binding protein (TBP) was obtained from Abcam Plc. (Abcam, Cambridge, UK). Horseradish peroxide-conjugated immunoglobulin $\mathrm{G}$ antibody was purchased from Vector Laboratories (Burlingame, MA, USA). The lactate dehydrogenase release (LDH) cytotoxicity detection kit was obtained from Takara Shuzo Co. (Shiga, Japan). All other reagents were purchased from Sigma (St. Louis, MO, USA), unless indicated.

\section{Extraction and isolation of DEK}

As previously described [25], the whole plant of the marine brown alga Ecklonia cava was prepared from the Jeju Island coast in the Republic of Korea. Briefly, the dried power of Ecklonia cava was extracted with $70 \%$ aqueous ethanol. The n-butanol fraction was performed by octadecyl silica gel column chromatography. The DEK was finally purified by LH-20 column chromatography and then confirmed by comparing the mass spectrometry, ${ }^{1} \mathrm{H}$ nuclear magnetic resonance (NMR), and ${ }^{13} \mathrm{C}-\mathrm{NMR}$ data [26].

\section{Cell culture}

Primary cortical neuron cultures were prepared from the cerebral cortices of gestation day 16 Sprague-Dawley rat embryos. The meninges-free rat cortices were triturated using fire-polished Pasteur pipettes. Cells were seeded into culture plates pre-coated with poly-L-lysine and cultured in Minimum Essential Media (Gibco BRL, Gaithersburg, MD, USA) containing 10\% fetal bovine serum (FBS), 45\% glucose, $25 \mathrm{mM}$ glutamate, $100 \mathrm{mM}$ sodium pyruvate, $100 \mathrm{U} / \mathrm{ml}$ penicillin, and $100 \mu \mathrm{g} / \mathrm{ml}$ streptomycin and kept at $37^{\circ} \mathrm{C}$ in a humidified atmosphere of $5 \% \mathrm{CO}_{2}$. After $24 \mathrm{~h}$ incubation, the culture medium was replaced by neurobasal media supplemented with 2\% B27 supplement, $200 \mathrm{mM} \mathrm{L-}$ glutamine, $100 \mathrm{U} / \mathrm{ml}$ penicillin, and $100 \mu \mathrm{g} / \mathrm{ml}$ streptomycin. The HT22 neuronal cell line [27] was generously supplied by Dr. B.H. Lee (Gachon University of Medicine and Science, Republic of Korea). HT22 cells were cultured in Dulbecco's modification of Eagle medium (Gibco BRL, Gaithersburg, MD, USA) supplemented with $10 \% \mathrm{FBS}, 100 \mathrm{U} / \mathrm{ml}$ penicillin, and $100 \mu \mathrm{g} / \mathrm{ml}$ streptomycin and maintained at $37^{\circ} \mathrm{C}$ in a humidified atmosphere of $5 \% \mathrm{CO}_{2}$. The study was approved by the Animal Care and Use Committee of Jeju National University (no. 2016-0029) and all experiments 
were performed in accordance with the guidelines.

\section{1,1-Diphenyl-2-picrylhydrazyl (DPPH) free radical scavenging assay}

As previously described [25], $10 \mu \mathrm{l}$ of DEK in various concentrations was added to $190 \mu \mathrm{l}$ of $0.15 \mathrm{mM} \mathrm{DPPH}$, and mixed vigorously. The mixture was incubated in the dark at room temperature for $2 \mathrm{~h}$, and the absorbance was read at $517 \mathrm{~nm}$ using a microplate reader (Sunrise; Tecan, Mannedorf, Switzerland).

\section{Intracellular ROS measurement}

As previously described [25], primary cortical neurons and HT22 neurons were seeded in 96-well tissue culture plates at $2 \times$ $10^{4}$ cells/well containing medium $(200 \mathrm{ml})$ after $12 \mathrm{~h}$ stabilization. After the addition of $20 \mu \mathrm{M}$ of 2',7'-dichlorofluorescein diacetate (DCF-DA), the fluorometric analysis was performed with the excitation/emission wavelength at $485 \mathrm{~nm} / 535 \mathrm{~nm}$ using a microplate reader (Spectra fluor; Tecan).

\section{LDH assay}

The cytotoxicity of DEK was measured with an LDH cytotoxicity detection kit (Takara Shuzo Co.) on a microplate reader (Sunrise), as previously described [28].

\section{MTT cell viability assay}

MTT (3-(4,5-dimethylthiazol-2-yl)-2,5-diphenyl tetrazolium bromide) was used to investigate the DEK effects on cell viabilities as previously described [28].

\section{Quantification of cellular ATP levels}

After treatment, the cells were harvested and then lysed with lysis buffer (120 mM NaCl, $40 \mathrm{mM}$ Tris [pH 8], 0.1\% NP 40) and centrifuged at $13,000 \times g$ for $15 \mathrm{~min}$. The supernatants were assayed for ATP content using luciferase/luciferin ATP determination kit (Molecular Probes, Eugene, OR, USA).

\section{Western blot analysis}

Western blot analysis was performed as described [28]. The protein bands were detected using an enhanced chemiluminescence Western blot detection kit (Amersham, Little Chalfont, UK). Nuclear proteins were prepared as previously described [28]. The membranes were probed with the following primary antibodies: HO-1 (1:1,000), Nrf2 (1:200), TBP (1:2,000), and $\beta$-actin $(1: 5,000)$. $\beta$-actin and TBP were used as each control for equal protein loading in whole cells and nuclear fractions, respectively.
Flow cytometric analysis of $\Delta \Psi_{\mathrm{m}}$, mitochondrial $\mathrm{Ca}^{2+}$ and ROS

JC-1 is a cell-permeable indicator for $\Delta \Psi_{\mathrm{m}}$ and membrane potential-dependently accumulated in active mitochondria. Rhod-2 AM, a cell-permeable AM form of Rhod-2, was used as a mitochondria-selective $\mathrm{Ca}^{2+}$ indicator. Upon $\mathrm{Ca}^{2+}$ binding, fluorescence intensities of Rhod-2 are dramatically increased (> 100fold). As cationic Rhod-2 shows potential-driven uptake into the mitochondria, it has been used as a selective indicator for mitochondrial $\mathrm{Ca}^{2+}$. The cationic MitoSOX Red is cell-permeable and also selectively targeted to the mitochondria. Once MitoSOX Red is oxidized by superoxide anions which are the predominant ROS in mitochondria, it exhibits red fluorescence. After treatment, the cells were loaded with JC-1 (5 $\mu \mathrm{M}, 30 \mathrm{~min})$, Rhod-2 AM ( $2 \mathrm{M}, 30$ min) and MitoSOX Red $(5 \mu \mathrm{M}, 20 \mathrm{~min})$ at $37^{\circ} \mathrm{C}$ to measure $\Delta \Psi_{\mathrm{m}}$, mitochondrial $\mathrm{Ca}^{2+}$ and ROS, respectively [29,30]. The loaded cells were washed with phosphate-buffered saline three times, and analyzed by flow cytometry using a FACS Calibur (Becton Dickinson, Franklin Lakes, NJ, USA).

\section{Confocal imaging analysis of mitochondrial ROS}

After treatment, HT22 neurons were loaded with the mitochondrial superoxide indicator MitoSOX Red ( $5 \mu \mathrm{M}, 20 \mathrm{~min})$ and Mito Tracker Green (50 nM, $30 \mathrm{~min}$ ), washed three times and imaged on a confocal laser scanning microscope (FV500; Olympus, Tokyo, Japan) using a cooled charge-coupled device camera controlled by Flow View 4.2 software (Olympus).

\section{Statistics analysis}

Data were expressed as mean value \pm standard error of mean. Statistical analyses were performed using Student t-test and oneway ANOVA followed by Bonferroni test. The differences between groups were considered to be statistically significant when $\mathrm{p}<0.05$.

\section{RESULTS}

\section{Neuroprotective effects of DEK on neuronal cell viability and morphological changes against glutamate toxicity}

We investigated whether DEK affected neuronal cell viability against glutamate toxicity. Both primary cortical neurons and HT22 neuronal cell line were pretreated with DEK for $1 \mathrm{~h}$ prior to glutamate stimulation. Then, primary cortical neurons were stimulated with glutamate $(100 \mu \mathrm{M})$ in the presence of different doses $(1,10,30$ and $50 \mu \mathrm{M})$ of DEK for $24 \mathrm{~h}$. In case of HT22 neurons, cells were stimulated with glutamate $(5 \mathrm{mM})$ for $12 \mathrm{~h}$. DEK 
below $100 \mu \mathrm{M}$ did not show any cytotoxicity as a chemical agent for treatment, based on MTT assay and LDH release assay (Fig. $1 \mathrm{~B}, \mathrm{C})$.

The results revealed that DEK markedly increased neuronal cell viability against glutamate toxicity in a dose-dependent manner in both the primary cortical neurons (Fig. 2A) and HT22 neurons (Fig. 2B). Glutamate-induced morphological changes were observed by phase contrast inverted microscopy. Retracted
A<smiles>Oc1cc(O)cc(Oc2c(O)cc(O)c3c2Oc2c(O)cc(Oc4cc(O)c(Oc5c(O)cc(O)c6c5Oc5c(O)cc(O)cc5O6)cc4O)cc2O3)c1</smiles>

B

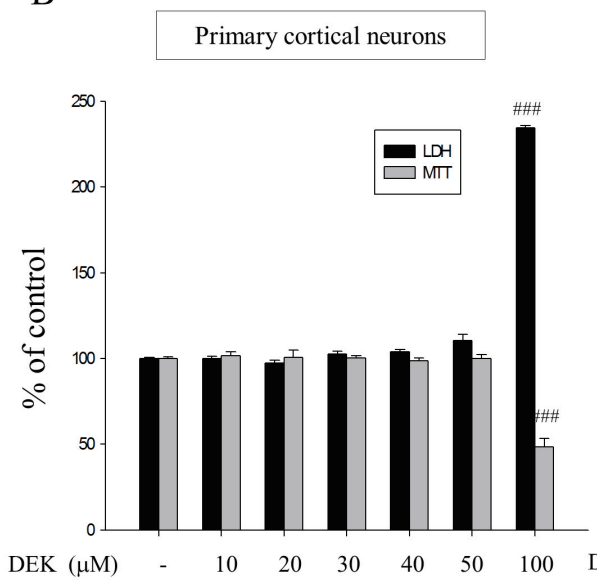

C

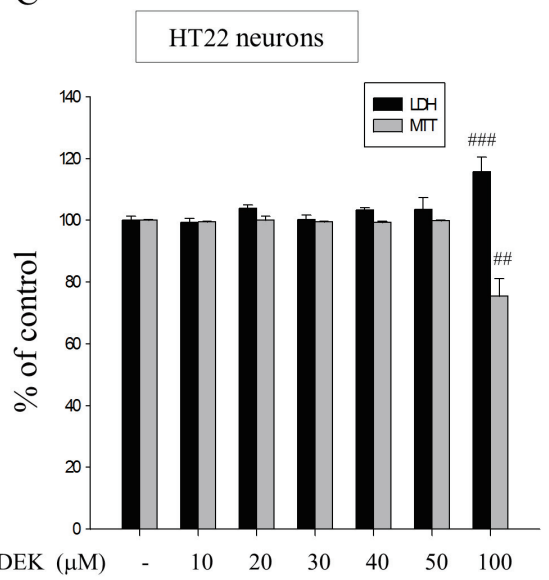

Fig. 1. Chemical structure and cytotoxicity test of DEK. (A) Chemical structure of DEK. (B) Cytotoxicity test of DEK in neurons. Different doses of DEK were treated for $25 \mathrm{~h}$ in primary cortical neurons and for $13 \mathrm{~h}$ in HT22 neurons. These treatment durations are the sum of co-treatment duration (24 $\mathrm{h}$ for primary cortical neurons and $12 \mathrm{~h}$ for HT22 cell line) and the DEK pretreatment duration ( $1 \mathrm{~h}$ ). The cytotoxicity of DEK was examined using the MTT assay and LDH release assay. DEK below $100 \mu \mathrm{M}$ did not show any cytotoxicity as a chemical agent for treatment, based on MTT assay and LDH release assay. Values were expressed as mean \pm standard error of mean of four samples in one independent experiment. ${ }^{\# \#} p<0.001$, as compared to the untreated control group. DEK, dieckol; MTT, 3-(4,5-dimethylthiazol-2-yl)-2,5-diphenyl tetrazolium bromide; LDH, lactate dehydrogenase release.
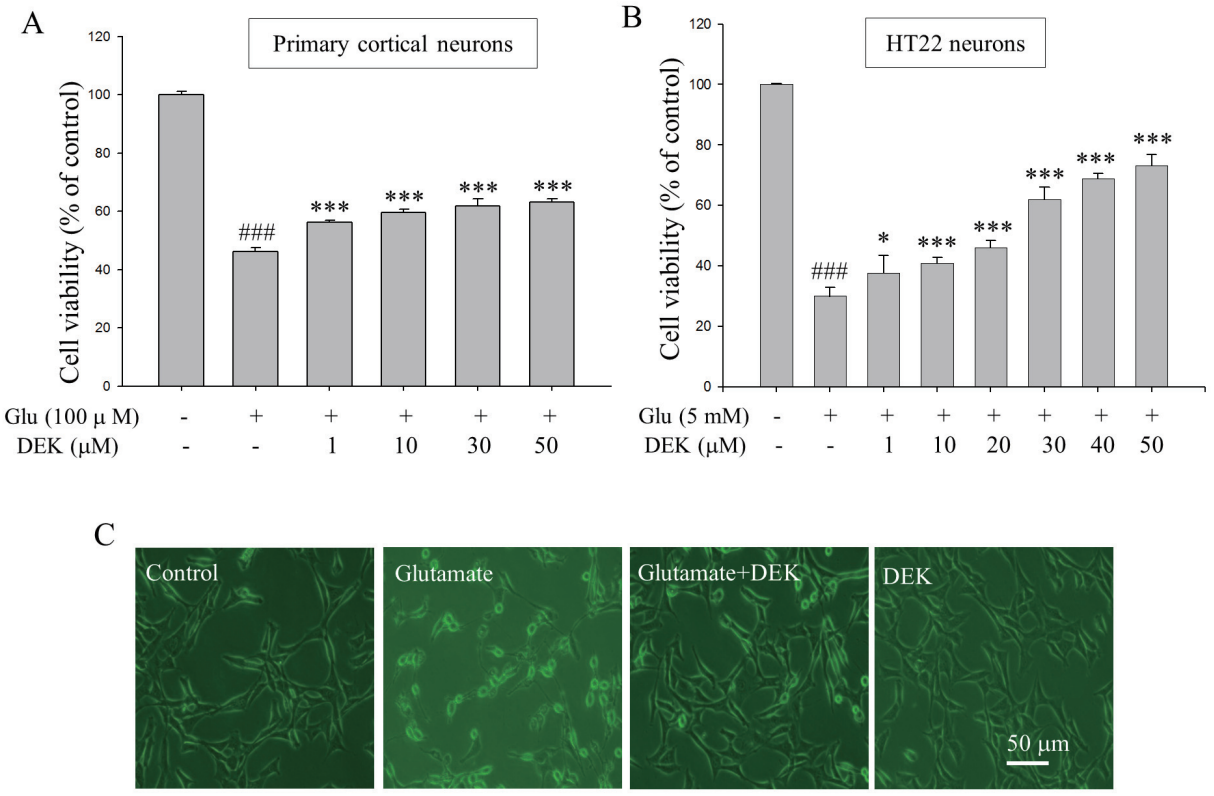

Fig. 2. Neuroprotective effects of DEK on neuronal cell viabilities and morphological changes against glutamate toxicity. (A and B) Both primary cortical neurons and HT22 neuronal cell line were pretreated with DEK for $1 \mathrm{~h}$ prior to glutamate stimulation. Then, primary cortical neurons were stimulated with glutamate $(100 \mu \mathrm{M})$ in the presence of different doses of DEK for $24 \mathrm{~h}$. In case of HT22 neurons, cells were stimulated with glutamate $(5 \mathrm{mM})$ for $12 \mathrm{~h}$. Neuroprotective effects of DEK against glutamate toxicity were evaluated using MTT cell viability assay in primary cortical neurons and HT22 neurons. (C) Representative phase contrast images indicating neuroprotective effects of DEK on glutamate-induced morphological changes in HT22 neurons. Scale bar, $50 \mu \mathrm{m}$. Values were expressed as mean \pm standard error of mean of four samples in one independent experiment. Statistical analyses were performed using one-way ANOVA followed by Bonferroni test. ${ }^{\# \#} p<0.001$, as compared to untreated control group; ${ }^{*} p<0.05$ and ${ }^{* *} \mathrm{p}<0.001$, as compared to glutamate alone-treated group. DEK, dieckol; Glu, glutamate; MTT, 3-(4,5-dimethylthiazol-2-yl)-2,5-diphenyl tetrazolium bromide. 
neurites and shrunken cell bodies were shown in the glutamatestimulated HT22 neurons, and DEK recovered glutamateinduced morphological deterioration (Fig. 2C). Taken together, these results suggest that DEK significantly protects glutamatestimulated neurons against glutamate toxicity-induced cell death and deterioration.

\section{ROS scavenging activities of DEK in glutamate- stimulated neurons}

We investigated using the DPPH free radical scavenging assay whether DEK had direct free-radical scavenging properties in a cell-free system. As shown in Fig. 3A, the DEK dose-dependently scavenged DPPH free radicals. Both primary cortical neurons and HT22 neuronal cell line were pretreated with DEK for $1 \mathrm{~h}$ prior to glutamate stimulation. Then, primary cortical neurons were stimulated with glutamate $(100 \mu \mathrm{M})$ in the presence of different doses $(1,10,30,40$, and $50 \mu \mathrm{M})$ of DEK for $24 \mathrm{~h}$. In case of HT22 neurons, cells were stimulated with glutamate $(5 \mathrm{mM})$ for $12 \mathrm{~h}$. The amounts of intracellular ROS generated by glutamate were detected by a spectrofluorometer using the ROS-sensitive fluorescent dye DCF-DA. The results demonstrated that glutamate markedly evoked intracellular ROS generation in both the primary cortical neurons (Fig. 3B) and HT22 neurons (Fig. 3C), and DEK strongly suppressed glutamate-induced intracellular ROS levels in a dose-dependent manner in both types of neurons.

\section{DEK attenuates glutamate-induced mitochondrial dysfunction}

Mitochondrial dysfunction leads to mitochondria-dependent cell death against glutamate toxicity, which includes mitochondrial $\mathrm{Ca}^{2+}$ overload, $\Delta \Psi_{\mathrm{m}}$ disruption, ATP depletion, abnormal electron transport, and ROS generation in the mitochondrial ETC. Therefore, we investigated whether DEK protected neurons from mitochondrial dysfunction in several mitochondrial parameters. Intracellular ATP levels were measured using a luciferase/ luciferin ATP determination kit. $\Delta \Psi_{\mathrm{m}}$, mitochondrial $\mathrm{Ca}^{2+}$, and ROS were measured using by flow cytometric analysis of JC-1, Rhod-2, and MitoSOX fluorescence, respectively.

HT22 neurons were pretreated with $\operatorname{DEK}(50 \mu \mathrm{M})$ for $1 \mathrm{~h}$, then stimulated with glutamate $(5 \mathrm{mM})$ in the presence of DEK for $12 \mathrm{~h}$. As shown in Fig. 4, DEK significantly rescued glutamate-induced ATP depletion (Fig. 4A), $\Delta \Psi_{\mathrm{m}}$ disruption (Fig. 4B), mitochondrial $\mathrm{Ca}^{2+}$ overload (Fig. 4C), and mitochondrial ROS generation (Fig. 4D). The inhibitory effects of DEK on mitochondrial ROS were also shown in confocal microscopic images (Fig. 4E). Dramatic accumulation of mitochondrial ROS stained with MitoSOX was visualized in a dotted pattern under confocal microscopy. Taken together, these results suggest that DEK significantly protects HT22 neurons against glutamate-induced mitochondrial dysfunction.
A

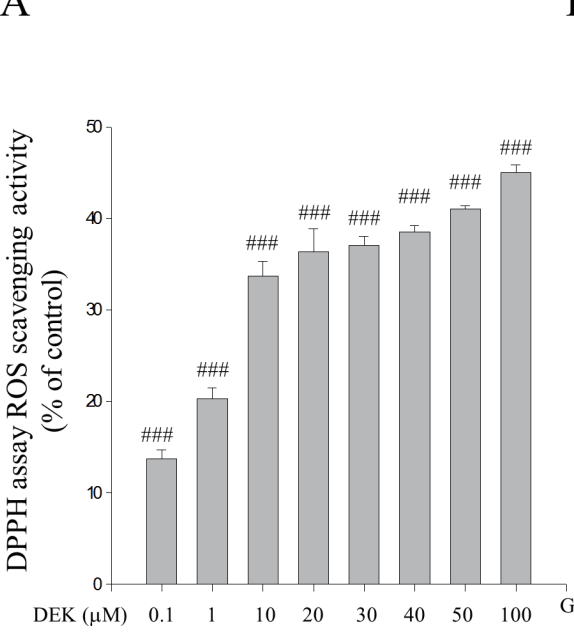

B

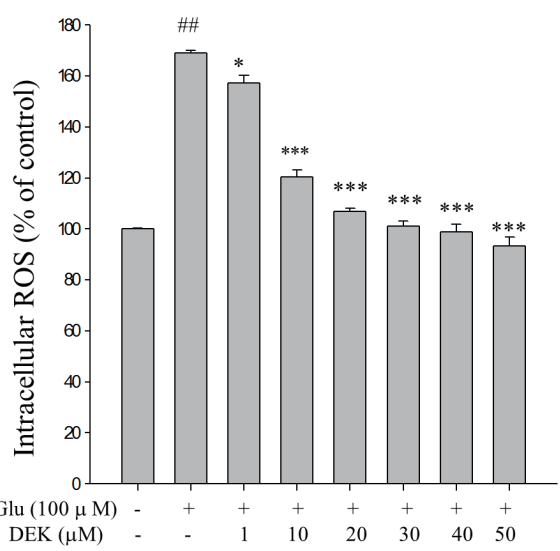

$\mathrm{C}$

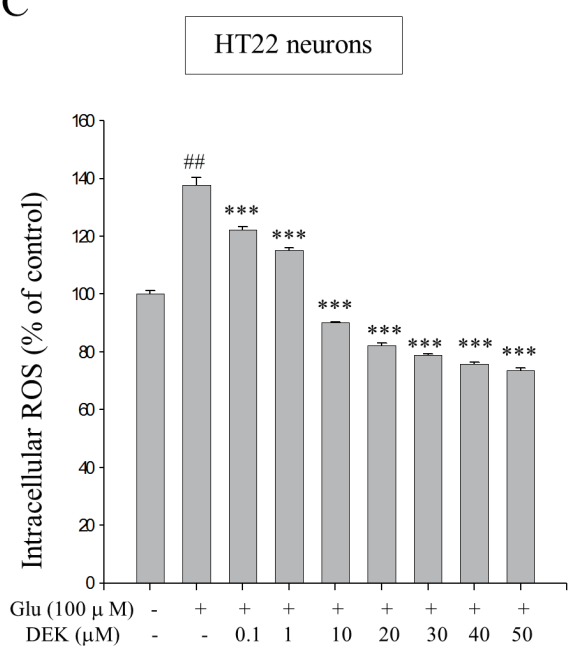

Fig. 3. ROS scavenging activities of DEK in glutamate-stimulated neurons. (A) Free radical scavenging activities of DEK in a cell-free system were performed using the DPPH assay. (B and C) Both primary cortical neurons and HT22 neuronal cell line were pretreated with DEK for $1 \mathrm{~h}$ prior to glutamate stimulation. Then, primary cortical neurons were stimulated with glutamate $(100 \mu \mathrm{M})$ in the presence of different doses of DEK for $24 \mathrm{~h}$. In case of HT22 neurons, cells were stimulated with glutamate $(5 \mathrm{mM})$ for $12 \mathrm{~h}$. Effects of DEK on glutamate-induced intracellular ROS generation were examined using a spectrofluorometer with the ROS-sensitive fluorescent dye DCF-DA. Values were expressed as mean \pm standard error of mean of four samples in one independent experiment. Statistical analyses were performed using one-way ANOVA followed by Bonferroni test. ${ }^{\#} p<0.01$ and ${ }^{\# \#} p<$ 0.001 , as compared to the untreated control group; ${ }^{*} p<0.05$ and ${ }^{* * *} p<0.001$, as compared to the glutamate alone-treated group. ROS, reactive oxygen species; DPPH, 1,1-diphenyl-2-picrylhydrazyl; DEK, dieckol; Glu, glutamate. 
A

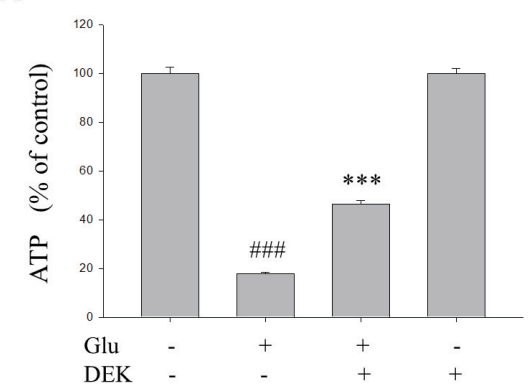

C

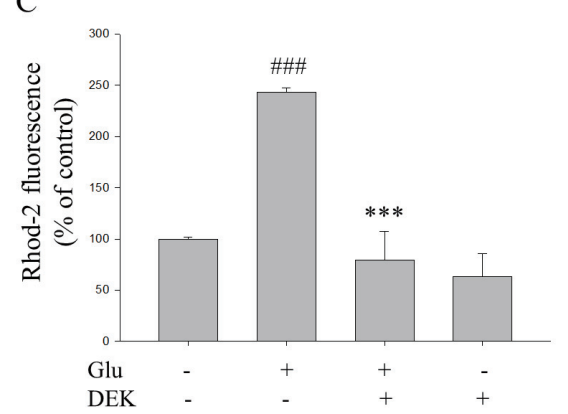

$\mathrm{D}$

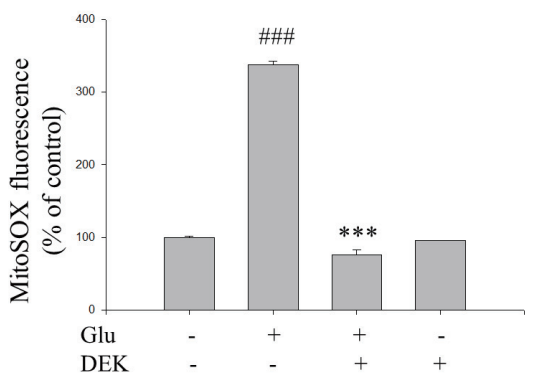

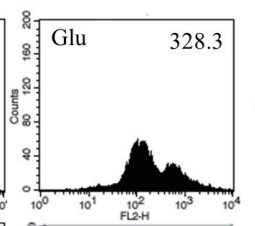
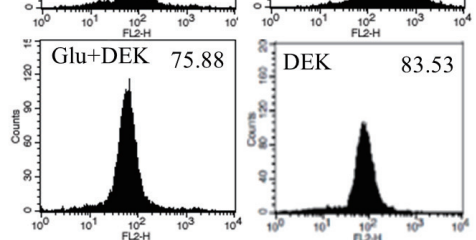

B
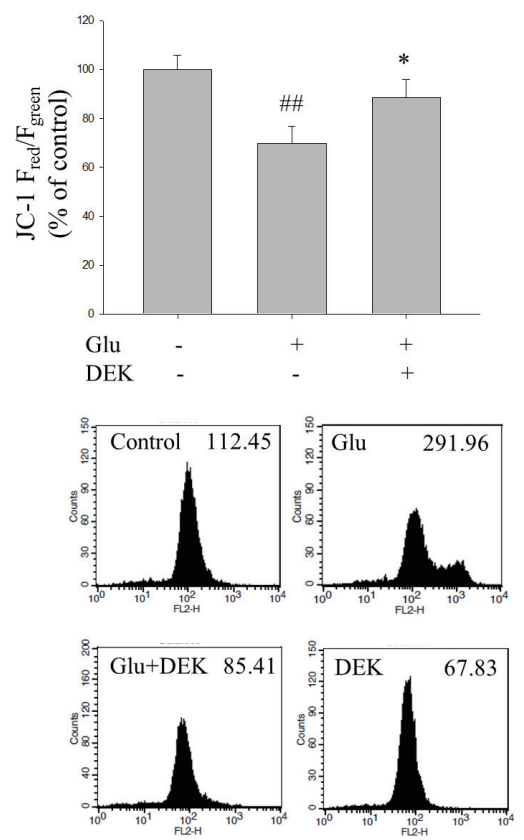

$\mathrm{E}$

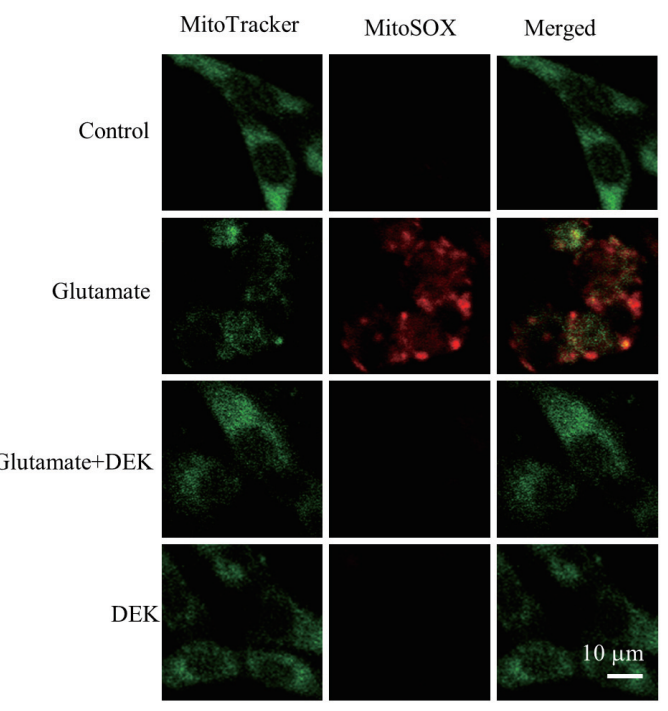

Fig. 4. DEK attenuates glutamate-induced mitochondria dysfunction. $\mathrm{HT} 22$ neurons were pretreated with DEK (50 $\mu \mathrm{M}$ ) for $1 \mathrm{~h}$ and then stimulated with glutamate $(5 \mathrm{mM})$ in the presence of DEK for $12 \mathrm{~h}$. Effects of DEK on glutamate-induced mitochondrial dysfunction were examined. (A) Intracellular ATP levels were measured using a luciferase/luciferin ATP determination kit. (B) The effects of DEK on glutamate-induced $\Delta \Psi_{m}$ disruption were analyzed by flow cytometry using JC-1. Figure shows the representative data of flow cytometry in the lower panel and their quantitative analyses in the upper panel. (C) The effects of DEK on glutamate-induced mitochondrial $\mathrm{Ca}^{2+}$ levels were analyzed by flow cytometry using Rhod-2. (D) The effects of DEK on glutamate-induced mitochondrial ROS generation were analyzed by flow cytometry using MitoSOX. Figure shows the representative data of flow cytometry in the lower panel and their quantitative analyses in the upper panel. (E) Representative confocal images of HT22 neurons loaded with MitoSOX were shown to demonstrate neuroprotective effects of DEK on glutamate-induced mitochondrial ROS generation. Mitochondria were stained with Mito Tracker Green. Scale bar, $50 \mu \mathrm{m}$. Values were expressed as mean \pm standard error of mean of four samples in one independent experiment. ${ }^{\# \#} p<0.01$ and ${ }^{\# \# \#} p<0.001$, as compared to untreated control group; ${ }^{*} p<0.05$ and ${ }^{* * *} p<0.001$, as compared to glutamate alone-treated group. ATP, adenine triphosphate; Glu, glutamate; DEK, dieckol; JC-1, 5,5',6,6'-tetrachloro-1,1',3,3'-tetraethylbenzimidazolocarbocyanine iodide; Rhod2, rhod-2 acetoxymethyl ester; ROS, reactive oxygen species; $\Delta \Psi_{m}$, mitochondrial membrane potential. MitoSOX and Mito Tracker Green; Invitrogen, Carlsbad, CA, USA. 


\section{DEK increases nuclear translocation of $\mathrm{Nrf2}$ and $\mathrm{HO}-1$ expression}

HO-1 plays an important anti-oxidant enzyme which detoxifies ROS and the phosphorylated Nrf2 translocates to the nucleus where it activates HO-1 gene transcription [19-21]. Therefore, the effects of DEK on the Nrf2/HO-1 axis as a cellular anti-oxidant defense system were investigated in HT22 neurons.

The cells treated with DEK $(10,20,30,40$, and $50 \mu \mathrm{M})$ for 12 $\mathrm{h}$ showed a dose-dependent increase in HO-1 protein expression (Fig. 5A). In addition, DEK dramatically increased protein expression levels of the transcription factor Nrf2 in the nuclear fraction, suggesting DEK-induced nuclear translocation of Nrf2. The maximal increase was shown at the 90 min time-point (Fig. 5B). Taken together, these results suggest that DEK markedly reduced intracellular ROS levels (Fig. 3B, C) against glutamate toxicity through the activation of the $\mathrm{Nrf} / \mathrm{HO}-1$ pathway (Fig. 5) as well as direct free radical scavenging activity (Fig. 3A).

\section{DISCUSSION}

The neuroprotective mechanisms of DEK against glutamateinduced mitochondrial dysfunction and neuronal cell viability against glutamate toxicity were investigated in this study. The results demonstrated that DEK exerts neuroprotective activities through direct free radical scavenging and Nrf2/HO-1 pathway activation against glutamate-induced mitochondrial dysfunction and subsequent mitochondria-dependent neuronal cell death.

Glutamate toxicity has been implicated in the pathogenesis of brain ischemia/stroke, traumatic brain injury, and neurodegenerative diseases such as Parkinson's, Alzheimer's, and Huntington's disease [16-18]. Therefore, the glutamate toxicity model has long been employed in these research fields. Two different types of neurons were used to induce a glutamate toxicity model in this study. Rat primary cortical neurons were stimulated with glutamate $(100 \mu \mathrm{M}$,) in the presence of DEK for $24 \mathrm{~h}$. In case of mouse hippocampal HT22 neuronal cell line, cells were stimulated with glutamate $(5 \mathrm{mM})$ for $12 \mathrm{~h}$. The dose and duration of glutamate treatment were determined depending upon cell types, based on the previous reports [31-33]. There are several different methods used to induce neuronal glutamate toxicity. The experimental conditions may differ according to the nature and strength of neurotoxic stimuli, neuronal cell types or particular populations. The differences/discrepancies in experimental conditions such as dose and duration of glutamate treatment between two types of cells, primary cortical neurons and HT22 neuronal cell line, are attributed to different expression pattern of glutamate receptors, especially NMDAR. HT22 cells lack in functional ionotropic glutamate receptor including NMDAR, compared to primary cultured neurons, and therefore need more glutamate stimulation (i.e., $5 \mathrm{mM}$ ) to induce glutamate toxicity $[32,33]$.

The two different pathways underlying glutamate toxicity mechanism are integrated in parallel in primary cultured neurons; NMDAR and/or mGluR-mediated excitotoxicity pathway and nonreceptor (i.e., cystine/glutamate antiporters)-mediated
A
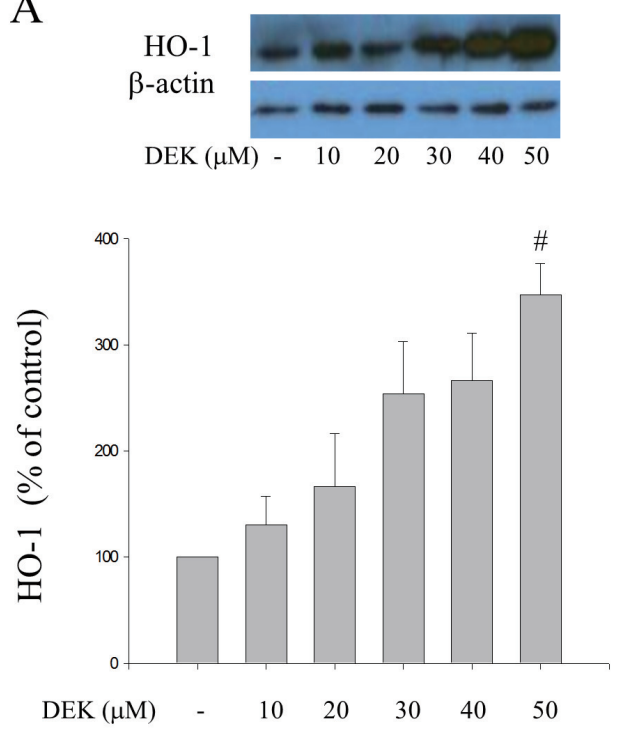

B
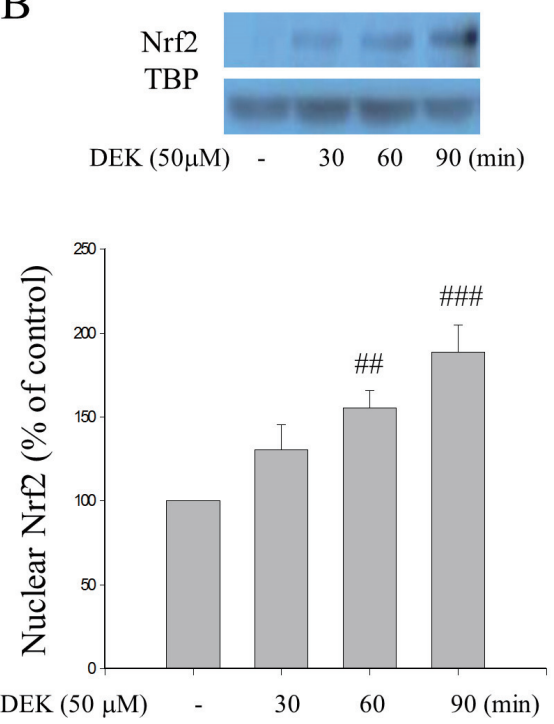

Fig. 5. DEK increases nuclear translocation of Nrf2 and HO-1 expression. Effects of DEK on HO-1 expression (A) and nuclear Nrf2 translocation (B) were examined using Western blot analysis. HT22 neurons were exposed to different doses of DEK for $12 \mathrm{~h}$. Total proteins were isolated for HO-1 and nuclear fractions were isolated at different time points for Nrf2. $\beta$-Actin and TBP were used as controls for equal protein loading in whole cells and nuclear fraction, respectively. Values were expressed as mean \pm standard error of mean of four samples in one independent experiment. Statistical analyses were performed using one-way ANOVA followed by Bonferroni test. ${ }^{\#} p<0.05,{ }^{\# \#} p<0.01$, and ${ }^{\# \#} p<0.001$, as compared to untreated control group. DEK, dieckol; Nrf2, nuclear factor-like 2; HO-1, heme oxygenase-1; TBP, TATA binding protein. 
oxidative stress pathway (Fig. 6). HT22 cell system has been used as an excellent model for nonreceptor-mediated oxidative stress by glutamate. Independently of NMDAR activation, cystine uptake from extracellular space is disturbed by high levels of extracellular glutamate in the brain, followed by GSH depletion $[27,33]$. In this study, we demonstrated that DEK exerts neuroprotective effects against glutamate toxicity in these two different cell systems. However, this study was not focused on either comparison or differences between two different cell models. Most experiments such as mitochondrial dysfunction and Nrf-2/HO-1 expression were accomplished in HT22 neuronal cell line. Only neuroprotective effects of DEK on cell viability and intracellular ROS levels against glutamate toxicity were also confirmed in primary cortical neurons, as well as in HT22 cells.

ROS serve as signaling molecules in certain redox-sensitive pathways in response to several extracellular stimuli under physiological conditions. For example, $\mathrm{H}_{2} \mathrm{O}_{2}$, one of the ROS best characterized as a signaling molecule, inactivates protein tyrosine phosphatases by oxidizing cysteine residues and thereby regulates protein tyrosine phosphorylation [19]. Localized ROS accumulation is tightly regulated according to cellular needs. However, high levels of ROS, if global and sustained, evoke mitochondriadependent neuronal cell death. Therefore, cellular ROS levels are precisely controlled by cellular antioxidant defense mechanisms including catalase, superoxide dismutase [34], and HO-1 [19], and a complex intracellular network of enzymes such as GSH, GSH peroxidase, peroxiredoxin, thioredoxin, and thioredoxin reductase [35]. Nevertheless, imbalance between ROS and antioxidants inside the cells results in mitochondrial dysfunction and neuronal cellular death.

Intracellular ROS levels are markedly increased in glutamatestimulated neurons through both glutamate receptor-mediated excitotoxicity pathway and nonreceptor-mediated oxidative glutamate toxicity pathway. It has been established that NADPH oxidase is an important down-stream protein of the glutamate receptors. The $\mathrm{Ca}^{2+}$ influx through NMDAR is linked to the activation of phosphoinositide 3 kinase (PI3K), followed by atypical protein kinase C zeta (PKC zeta) [36,37]. Extensive NMDAR activation leads to NADPH oxidase-induced superoxide formation by the phosphorylation of the cytosol subunit $\mathrm{p} 47^{\text {phox }}$ mediated by PI3K and atypical PKC zeta. Therefore, NMDAR and/or mGluRmediated intracellular $\mathrm{Ca}^{2+}$ influx and NADPH oxidase-dependent ROS are evaluated as triggering events in the mechanisms underlying glutamate receptor-mediated excitotoxicity [4,36,37].

Imbalance between ROS and cellular anti-oxidant enzyme system results in mitochondrial dysfunction and neuronal cellular death against glutamate toxicity. We demonstrated that DEK markedly reduced intracellular ROS levels (Fig. 3B, C) and mito-

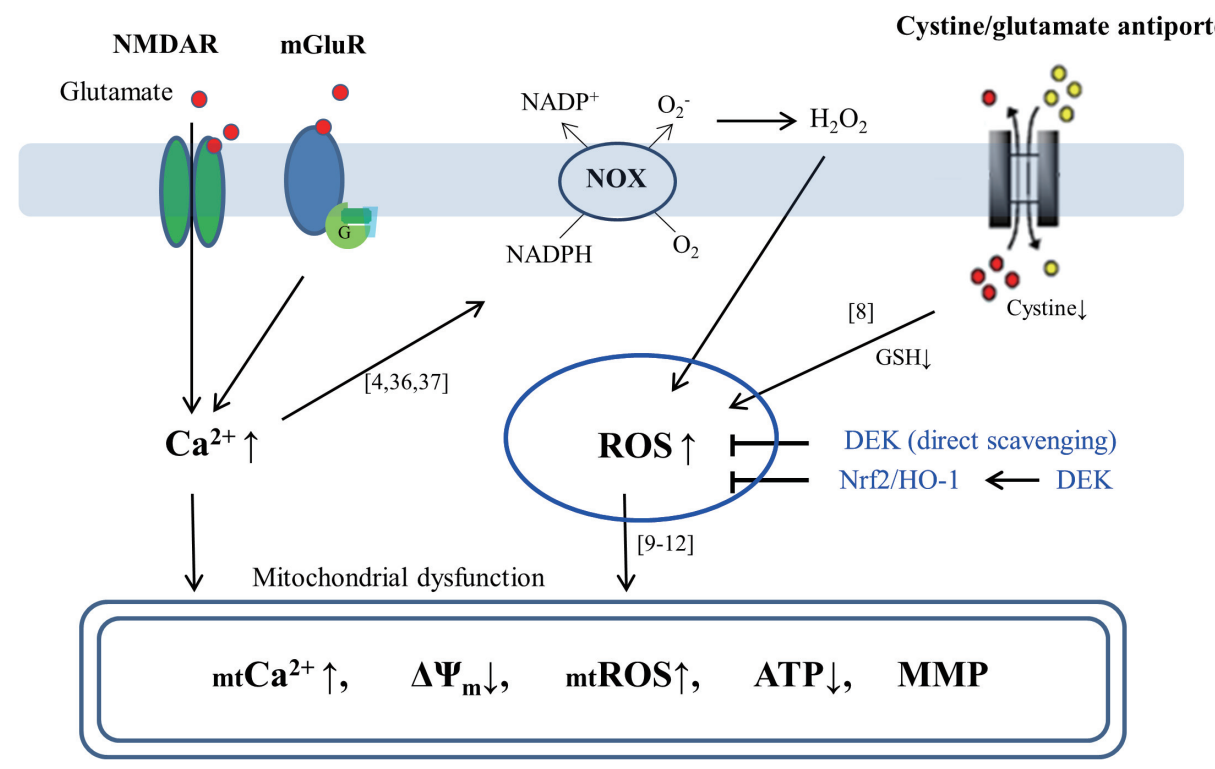

Fig. 6. Schematic diagram on neuroprotective effects of DEK against glutamate-induced neuronal cell death. There are two pathways underlying glutamate toxicity mechanism integrated in parallel in neurons; receptor-mediated excitotoxicity pathway and nonreceptor-mediated oxidative stress pathway. Increases of intracellular $\mathrm{Ca}^{2+}$ and $\mathrm{ROS}$ are triggering events in mitochondrial $(\mathrm{mt})$ dysfunction and neuronal cell death against glutamate toxicity. Glutamate-induced intracellular $\mathrm{Ca}^{2+}$ increase is evoked mainly through NMDAR and $\mathrm{G}$ protein-coupled mGluR. Intracellular glutamateinduced ROS generation is induced through NOX and cystine/glutamate antiporters in the initial state. DEK exerted neuroprotective activities against glutamate toxicity through direct ROS scavenging and activation of the Nrf-2/HO-1 pathway as a cellular anti-oxidant defense system in this study. Reference numbers are shown in the known signaling pathways. NMDAR, N-methyl-D-aspartate receptors; mGluR, metabotropic glutamate receptors; NADPH, nicotinamide adenine dinuclelotide phosphate; NOX, NADPH oxidase; GSH, glutathione; ROS, reactive oxygen species; DEK, dieckol; Nrf2, nuclear factor-like 2; HO-1, heme oxygenase-1; $\Delta \Psi_{m}$, mitochondrial membrane potential; ATP, adenine triphosphate; MMP, mitochondrial membrane permeabilization. 
chondrial ROS levels (Fig. 4D, E), against glutamate toxicity. DEK showed direct free radical scavenging activity in a cell-free system, as shown in DPPH assay (Fig. 3A). In addition, we revealed that DEK activated the $\mathrm{Nrf} 2 / \mathrm{HO}-1$ axis as a cellular anti-oxidant defense system in HT22 neurons (Fig. 5). Taken together, these results suggest that neuroprotective mechanisms of DEK against glutamate toxicity are largely based on the reduction of ROS levels through the activation of the Nrf2/HO-1 pathway (Fig. 5) as well as direct free radical scavenging activity (Fig. 3A).

As shown in Fig. 6, glutamate toxicity-induced increase of intracellular ROS levels finally induces mitochondrial dysfunction, which includes mitochondrial overload of $\mathrm{Ca}^{2+}$, and ROS, $\Delta \Psi_{\mathrm{m}}$ disruption, a second boost of ROS generation in ETC, ATP depletion. It is suggested that the action sites of DEK may be intracellular, as shown in Fig. 6. DEK has multiple phenol ring structures. Based on the chemical structure (Fig. 1A), it is possible that DEK possess both hydrophobic and hydrophilic properties. Multiple benzenoid ring structures underlie the hydrophobic property of DEK while hydroxy $(-\mathrm{OH})$ functional groups may allow DEK hydrophilic. Regarding this issue, it was reported that rhodaminelabelled DEK was observed inside the cells on a fluorescence microscope, when treated outside the cells [38]. Taken together, it is suggested that the hydrophobic DEK may rapidly diffuse across cell membranes so that they can reach intracellular sites of action.

In summary, we demonstrated here that DEK exerted neuroprotective activities against glutamate toxicity in both the primary cortical neurons and HT22 neurons through direct ROS scavenging and activation of the $\mathrm{Nrf}-2 / \mathrm{HO}-1$ pathway as a cellular anti-oxidant defense system. The results suggest that DEK may be a promising neuroprotective agent against glutamate toxicityrelated conditions implicated in brain ischemia/stroke, traumatic brain injury, and neurodegenerative diseases.

\section{ACKNOWLEDGEMENTS}

This research was supported by the Basic Science Research Program through the National Research Foundation of Korea (NRF) funded by the Ministry of Education, Science, and Technology (NRF-2013R1A1A2013585 and NRF-2015R1D1A1A01061010).

\section{CONFLICTS OF INTEREST}

The authors declare no conflicts of interest.

\section{REFERENCES}

1. Choi DW. Glutamate neurotoxicity and diseases of the nervous system. Neuron. 1988;1:623-634.

2. Orrenius S, Zhivotovsky B, Nicotera P. Regulation of cell death: the calcium-apoptosis link. Nat Rev Mol Cell Biol. 2003;4:552-565.

3. Duchen MR. Mitochondria, calcium-dependent neuronal death and neurodegenerative disease. Pflugers Arch. 2012;464:111-121.

4. Ha JS, Lee JE, Lee JR, Lee CS, Maeng JS, Bae YS, Kwon KS, Park SS, Nox4-dependent $\mathrm{H}_{2} \mathrm{O}_{2}$ production contributes to chronic glutamate toxicity in primary cortical neurons. Exp Cell Res. 2010; 316:16511661.

5. Peng TI, Jou MJ. Oxidative stress caused by mitochondrial calcium overload. Ann N Y Acad Sci. 2010;1201:183-188.

6. Murphy TH, Miyamoto M, Sastre A, Schnaar RL, Coyle JT. Glutamate toxicity in a neuronal cell line involves inhibition of cystine transport leading to oxidative stress. Neuron. 1989;2:1547-1558.

7. Tobaben S, Grohm J, Seiler A, Conrad M, Plesnila N, Culmsee C. Bid-mediated mitochondrial damage is a key mechanism in glutamate-induced oxidative stress and AIF-dependent cell death in immortalized HT-22 hippocampal neurons. Cell Death Differ. 2011:18:282-292

8. Li Y, Maher P, Schubert D. A role for 12-lipoxygenase in nerve cell death caused by glutathione depletion. Neuron. 1997;19:453-463.

9. Zha J, Weiler S, Oh KJ, Wei MC, Korsmeyer SJ. Posttranslational Nmyristoylation of BID as a molecular switch for targeting mitochondria and apoptosis. Science. 2000;290:1761-1765.

10. Pei Y, Xing D, Gao X, Liu L, Chen T. Real-time monitoring full length bid interacting with Bax during TNF-alpha-induced apoptosis. Apoptosis. 2007;12:1681-1690.

11. Kroemer G, Galluzzi L, Brenner C. Mitochondrial membrane permeabilization in cell death. Physiol Rev. 2007;87:99-163.

12. Susin SA, Lorenzo HK, Zamzami N, Marzo I, Snow BE, Brothers GM, Mangion J, Jacotot E, Costantini P, Loeffler M, Larochette N, Goodlett DR, Aebersold R, Siderovski DP, Penninger JM, Kroemer G. Molecular characterization of mitochondrial apoptosis-inducing factor. Nature. 1999;397:441-446.

13. Susin SA, Daugas E, Ravagnan L, Samejima K, Zamzami N, Loeffler M, Costantini P, Ferri KF, Irinopoulou T, Prévost MC, Brothers G, Mak TW, Penninger J, Earnshaw WC, Kroemer G. Two distinct pathways leading to nuclear apoptosis. J Exp Med. 2000;192:571580 .

14. Cregan SP, Fortin A, MacLaurin JG, Callaghan SM, Cecconi F, Yu SW, Dawson TM, Dawson VL, Park DS, Kroemer G, Slack RS. Apoptosis-inducing factor is involved in the regulation of caspaseindependent neuronal cell death. J Cell Biol. 2002;158:507-517.

15. Slemmer JE, Zhu C, Landshamer S, Trabold R, Grohm J, Ardeshiri A, Wagner E, Sweeney MI, Blomgren K, Culmsee C, Weber JT, Plesnila N. Causal role of apoptosis-inducing factor for neuronal cell death following traumatic brain injury. Am J Pathol. 2008;173:1795-1805.

16. Valencia A, Sapp E, Kimm JS, McClory H, Reeves PB, Alexander J, Ansong KA, Masso N, Frosch MP, Kegel KB, Li X, DiFiglia M. Elevated NADPH oxidase activity contributes to oxidative stress and cell death in Huntington's disease. Hum Mol Genet. 2013;22:11121131.

17. Cristóvão AC, Guhathakurta S, Bok E, Je G, Yoo SD, Choi DH, Kim YS. NADPH oxidase 1 mediates $\alpha$-synucleinopathy in Parkinson's disease. J Neurosci. 2012;32:14465-14477.

18. Choi BY, Jang BG, Kim JH, Lee BE, Sohn M, Song HK, Suh SW. Prevention of traumatic brain injury-induced neuronal death by inhibition of NADPH oxidase activation. Brain Res. 2012;1481:49-58.

19. Alam J, Stewart D, Touchard C, Boinapally S, Choi AM, Cook JL. 
Nrf2, a Cap'n'Collar transcription factor, regulates induction of the heme oxygenase-1 gene. J Biol Chem. 1999;274:26071-26078.

20. Nguyen T, Sherratt PJ, Pickett CB. Regulatory mechanisms controlling gene expression mediated by the antioxidant response element. Annu Rev Pharmacol Toxicol. 2003;43:233-260.

21. Nguyen T, Sherratt PJ, Nioi P, Yang CS, Pickett CB. Nrf2 controls constitutive and inducible expression of ARE-driven genes through a dynamic pathway involving nucleocytoplasmic shuttling by Keap1. J Biol Chem. 2005;280:32485-32492.

22. Kim AR, Shin TS, Lee MS, Park JY, Park KE, Yoon NY, Kim JS, Choi JS, Jang BC, Byun DS, Park NK, Kim HR. Isolation and identification of phlorotannins from Ecklonia stolonifera with antioxidant and anti-inflammatory properties. J Agric Food Chem. 2009;57:3483-3489.

23. Koirala P, Jung HA, Choi JS. Recent advances in pharmacological research on Ecklonia species: a review. Arch Pharm Res. 2017; 40:981-1005.

24. Myung CS, Shin HC, Bao HY, Yeo SJ, Lee BH, Kang JS. Improvement of memory by dieckol and phlorofucofuroeckol in ethanoltreated mice: possible involvement of the inhibition of acetylcholinesterase. Arch Pharm Res. 2005;28:691-698.

25. Cui Y, Park JY, Wu J, Lee JH, Yang YS, Kang MS, Jung SC, Park JM, Yoo ES, Kim SH, Ahn Jo S, Suk K, Eun SY. Dieckol attenuates microglia-mediated neuronal cell death via ERK, Akt and NADPH oxidase-mediated pathways. Korean J Physiol Pharmacol. 2015;19:219228.

26. Li Y, Qian ZJ, Ryu B, Lee SH, Kim MM, Kim SK. Chemical components and its antioxidant properties in vitro: an edible marine brown alga, Ecklonia cava. Bioorg Med Chem. 2009;17:1963-1973.

27. Breyer A, Elstner M, Gillessen T, Weiser D, Elstner E. Glutamateinduced cell death in neuronal HT22 cells is attenuated by extracts from St. John's wort (Hypericum perforatum L.). Phytomedicine. 2007;14:250-255.

28. Cui Y, Wu J, Jung SC, Park DB, Maeng YH, Hong JY, Kim SJ, Lee SR, Kim SJ, Kim SJ, Eun SY. Anti-neuroinflammatory activity of nobiletin on suppression of microglial activation. Biol Pharm Bull. 2010;33:1814-1821.

29. Wu JJ, Cui Y, Yang YS, Jung SC, Hyun JW, Maeng YH, Park DB, Lee
SR, Kim SJ, Eun SY. Mild mitochondrial depolarization is involved in a neuroprotective mechanism of Citrus sunki peel extract. Phytother Res. 2013;27:564-571.

30. Lee JH, Amarsanaa K, Wu J, Jeon SC, Cui Y, Jung SC, Park DB, Kim SJ, Han SH, Kim HW, Rhyu IJ, Eun SY. Nobiletin attenuates neurotoxic mitochondrial calcium overload through $\mathrm{K}^{+}$influx and $\Delta \Psi_{\mathrm{m}}$ across mitochondrial inner membrane. Korean J Physiol Pharmacol. 2018;22:311-319.

31. Zhang Y, Bhavnani BR. Glutamate-induced apoptosis in neuronal cells is mediated via caspase-dependent and independent mechanisms involving calpain and caspase-3 proteases as well as apoptosis inducing factor (AIF) and this process is inhibited by equine estrogens. BMC Neurosci. 2006;7:49.

32. Noh HS, Hah YS, Nilufar R, Han J, Bong JH, Kang SS, Cho GJ, Choi WS. Acetoacetate protects neuronal cells from oxidative glutamate toxicity. J Neurosci Res. 2006;83:702-709.

33. Kang TH, Bae KH, Yu MJ, Kim WK, Hwang HR, Jung H, Lee PY, Kang S, Yoon TS, Park SG, Ryu SE, Lee SC. Phosphoproteomic analysis of neuronal cell death by glutamate-induced oxidative stress. Proteomics. 2007;7:2624-2635.

34. Azadmanesh J, Borgstahl GEO. A review of the catalytic mechanism of human manganese superoxide dismutase. Antioxidants (Basel). 2018;7:25.

35. Chen C, Li L, Zhou HJ, Min W. The role of NOX4 and TRX2 in angiogenesis and their potential cross-talk. Antioxidants (Basel). 2017;6:42.

36. Brennan AM, Suh SW, Won SJ, Narasimhan P, Kauppinen TM, Lee $\mathrm{H}$, Edling Y, Chan PH, Swanson RA. NADPH oxidase is the primary source of superoxide induced by NMDA receptor activation. Nat Neurosci. 2009;12:857-863.

37. Brennan-Minnella AM, Shen Y, El-Benna J, Swanson RA. Phosphoinositide 3-kinase couples NMDA receptors to superoxide release in excitotoxic neuronal death. Cell Death Dis. 2013;4:e580.

38. Kwak JH, He Y, Yoon B, Koo S, Yang Z, Kang EJ, Lee BH, Han SY, Yoo YC, Lee KB, Kim JS. Synthesis of rhodamine-labelled dieckol: its unique intracellular localization and potent anti-inflammatory activity. Chem Commun (Camb). 2014;50:13045-13048. 